\title{
Pure Relationality as a Sociological Theory of Communication
}

\author{
Sam Whimster* \\ Global Policy Institute, London Metropolitan University, London, United Kingdom
}

In order to explain the success of populist politicians use of social media, we need to subtract the social from relationality and separate social relationships from network theory applications. A pure theory of relationality is suggested by Werner Heisenberg's breakthrough in quantum mechanics. It is argued that sociology, to its detriment, has failed to incorporate a theory of communication, one adequate to the explosion of social media and the recent rise of populist politics, here instanced by Donald Trump. Realizing the underlying importance of communication technology in all social relationships, and treating these two aspects in a complementary fashion, is the purpose of this essay in sociological theory.

\section{OPEN ACCESS}

Edited by:

Jan Balon,

Institute of Philosophy (ASCR),

Czechia

Reviewed by:

Raquel Andrade Weiss,

Federal University of Rio Grande do Sul (UFRGS), Brazil

William Outhwaite,

Newcastle University,

United Kingdom

*Correspondence:

Sam Whimster

swhimster@gmail.com

Specialty section:

This article was submitted to

Sociological Theory,

a section of the journal

Frontiers in Sociology

Received: 25 August 2017

Accepted: 11 January 2018

Published: 30 January 2018

Citation:

Whimster S (2018) Pure Relationality as a Sociological Theory of Communication.

Front. Sociol. 3:1.

doi: 10.3389/fsoc.2018.00001
Keywords: relationality, network theory, communication, Donald Trump, populist politics

\section{LEARNING FROM QUANTUM MECHANICS}

Excerpting a statement from network theory, a core idea of relationality is as follows: "An axiom of the social network approach to understanding social interaction is that social phenomena should be primarily conceived and investigated through the properties of relations between and within units, instead of the properties of these units themselves" (Wikipedia entry "Social network"). The established textbook reads, "Relations are not the properties of agents, but of the relational systems of agents built up from connected pairs of interacting agent" (Scott, 2017) (p. 4).

These statements imitate Werner Heisenberg's formulation of quantum mechanics (in 1927) concerning the movement of an electron from one orbit to another. Sub-atomic particles "are described not by their position at every moment but only by their position at particular instants: the instants in which they interact with something else." [...] "Electrons don't always exist. They exist when they interact. They materialize in a place when they collide with something else" (Rovelli, 2016) (p. 100).

Referencing Heisenberg gives us considerable license to push the envelope on the sociological theory of relationality; to the extent of re-defining what we mean by the social in relationality. The license is, however, limited and we cannot expect to match social theories to the strange behavior of electrons as formulated by quantum theory. Humans are very large macromolecules, directly observable and causal agents. While their behavior might be unpredictable, we as social theorists are not faced the same problem of indeterminancy. Instead this paper re-thinks what we assume to be the nature of the social by borrowing some of the conceptual thinking that attaches to relationality and granularity in quantum physics. I certainly do not advance as far as Gerhard Wagner who is applying quantum mechanics to the behavior of neurons in the brain in an attempt to reach a new version of Humean causality (Wagner, 2012) (pp. 20-29).

So this is not an intellectual effort to reduce social theory to theories taken from the natural sciences. Rather, I am following the suggestions recently put forward by Swedberg (2014) of devising, imaginatively, heuristics in order to think about the social in new ways. Werner Heisenberg is an inspiration in this sense, especially the well-known anecdote of him puzzling over the movement of electrons while sauntering through a Copenhagen park one evening. He watched a passer-by 
fade into invisibility as the person walked beyond the arc of light given by a street lamp, and then some short time later the person re-appeared under the next lamp along the path. It was, of course, the same person who re-appeared at the next pool of light. Electrons do more than disappear out of sight, they cease to exist. There is no continuous determinable trajectory of an electron. Emboldened by this idea-a heuristic-he then heroically worked out the maths (Pais, 1991) (pp. 304-309).

The heuristic I am emboldened by is to think as if the social may only exist at the point of contact between two persons. As the physicist Rovelli puts it in respect to electrons (which I naively and erroneously supposed to move in continuous orbits that are separated by quantum leaps): quantum mechanics "doesn't describe where there is a particle but how the particle show itself to others. The world of existent things is reduced to a realm of possible interactions. Reality is reduced to interaction. Reality is reduced to relation" (Rovelli, 2016) (p. 115).

As sociological theorists, we presume the social as existent, as always there. I will argue that a theory of pure relationality should only invoke the social at the point of collision. This is in line with my opening excerpt above: "social phenomena should be primarily conceived and investigated through the properties of relations between and within units..." Sociological (and social) theorists have long argued that the social entity be approached by the relationality between units, and not that individuals display intrinsic social attributes. Psychoanalytic theory has a nice quip to illustrate the point: "There is no such thing as an infant"-only maternal care (Winnicott, 1960) (p. 586). This is a more rigorous application of the injunction, but one that tends more generally not to be consistently followed. In social network analysis, pure relationality is usually discarded. What network sociologists do instead is to track existing social relationships and map them empirically and mathematically. I shall give two examples of this.

\section{SEPARATING RELATIONALITY FROM SOCIAL RELATIONSHIPS}

In a widely disseminated article Mucha (2003) deliberately overlaps social relations with social relationships. Basically, he was calling for a greater appreciation of the micro-sociology of relationships, a project started by Simmel in his 1908 book Sociology, elaborated by Weber in his Economy and Society, and further contributed to by Florian Znaniecki. These authors "looked for concepts referring to elementary units of the social realm and later built out of them, in a systematic way, concepts referring to larger social systems." These ideas "belong to a kind of interpretative sociology which has been looking not only for a subjective sense of social phenomena, but also for their causal explanations" (Mucha, 2003) (pp. 2-3). My only objection to Mucha's laudable plan to build sociology upwards from a social relationship base is that he calls this social relations. The title of his article reads "The concept of 'social relations' in classic analytical interpretative sociology: Weber and Znaniecki." My argument is that relationality and social relationships follow different theoretical principles. There is insufficient agreement in sociology about how these different theories are termed, and overlap and hence confusion remains. I will shortly clarify what I take to be the social in social relationship theory.

My other example is taken from Social Capital by Nan Lin which seems to be fairly typical of the way in which network theorists piggy-back on social relationship theories. This would not have worried Mucha, because that was the general direction in which he wanted sociology to proceed. Nan argues "that actions motivated by expressive and instrumental needs propel interactions with others beyond primordial groups so that social capital may be accessed." Expressive and instrumental action types derive from the interpretative sociology of Weber and others. Meaning is assumed at the level of social action and then has to be carried upwards "mediated through certain middle-level structures and processes." This is where network analysis steps in. As Nan comments, "Many scholars have used network analysis to delineate this micro-to macro process, including Coleman, White, Granovetter .... and many others." Purposive action leads to the "formation of social networks (first the primary group and then secondary ties)..." (Nan, 2001) (p. 184).

An interpretive sociology should have no objection to this manner of proceeding. And from my perusal of patterning theories of networks, they are by majority extensions of pre-existing social relationships. For reasons of space, I address network analysis as a subsection of the much wider field of relational sociology (for example, Powell and Dépelteau, 2013). Network theory is empirically important and adds to our sociological knowledge, but it remains very much mapping and tracking exercises of pretty standard forms of social relationships. What I am pushing for is a method that starts with networks of relationality and then ask how is the social created/affected/re-constituted. Interpretive sociology was a breakthrough in the creation of classical social theory and it opened up much of history as well as the formation of modernity itself to proper sociological analysis. That, in my view, is not sufficient for today where there has been an explosion in relationality based on the technology of digital communication. Weber and his contemporaries lived in a world of face to face communication, the letter, the newspaper, and the book. We increasingly do not. Classical sociology remains valid but is unable to comprehend the relationality of new forms of communication.

Let me illustrate this point. It is quite feasible to analyze the Donald Trump phenomenon in terms of Weber's political sociology, and recently outline in the editorial of Max Weber Studies 17.1 (www.maxweberstudies.org). Weber's theory of democracy was built around the figure of the demagogue who (in ancient Greece) by force of argument in the agora-and aided by graffiti and poster-was able to challenge the existing oligarchy. Weber saw the same phenomenon on the streets of Munich in 1918-1919-the socialist Kurt Eisner and the right-wing Freikorps. Weber was contemptuous of these forms of direct democracy - the demagogues died in the gutter of street politics being one of his more unpleasant utterances. The charismatic leader was defined by his or her oratory in front of an audience limited in size (in principle) to hearing distance. Of Kurt Eisner's charismatic oratory in the Theresienwiese (parkland), Hopkins (2007), p.206, writes: "charisma is a feature of the situation, more than just a magnetic personality with a silver tongue" (Hopkins, 
2007) (p. 206)." Direct democracy is a direct relationship between leader and following, but one situationally bounded.

The twittersphere is obviously crucial to Donald Trump's spectacular rise to the US presidency, but alongside this he can also be situated within a classical tradition of American populism-Pat Buchanan, Huey Long, William Jennings Bryan, etc. Big American capitalism has frequently displayed some nasty traits, mostly on the extension and withdrawal of bank credit, and American voters have reacted with populist and evangelical movements. What is notable from the above list of populists is that none has ever succeeded to high office. Trump's ascent was achieved through the delegitimation of elite political discourse. Twitter and social media re-defined the relational impact on politics. Previous political legitimacy resided in well-defined and practised social relationships-appeals to sectional interests, conservative or social-democratic values, intra-party democracy and procedure-made through old media. The urgent inquiry is to ask what is the nature of relationality that, for me, resides in communication.

\section{THE SOCIAL IN SOCIAL RELATIONSHIPS}

I will turn to relationality in the second part of this paper. First, I want to set up the theory of social relationships in a way that its separateness from relationality becomes distinct.

Social relationships are built from and between units, more usually social actors. At the minimum, two social actors form a social relationship based on meaning. Changes in meaning alter the nature of the social relationship, rather like the dial on a radio set. In Weber's most abstract typification these meanings vary from traditional, affectual to forms of rationality. These basic sociological concepts are the building blocks of more complex theories-of the state, of society, of the firm, etc.

A social relationship is a bond between, at minimum, two people. According to Weber, the bond is formed through both parties' orientation to a common meaning. Stripped down to its essentials, a social relationship is a meaning-link between two positions. One way of thinking about this is to say that each party is a meaning generator.

How meaning is generated and linked up has been a topic of penetrating debates in classical sociology. Phenomenology, pragmatism, and interpretive sociology each have their own answer. The commonality here is that social relationships flow from the units, the actors, involved. How meaning is generated and how links are formed-a topic that very much occupied Schütz and symbolic interactionists-is not a simple matter. But on the ground, littered everywhere, are meaningful relationships. This is the granularity that underlies the sociology of social relationships and one way of thinking about granularity is to think, heuristically, of actors or individuals as posited in a field constituted of meaning.

Analytically, we could then proceed to the unitization of meaning. On a vertical scale, meaning could be valorized from low to high, and in a further operation it could be differentiated as intensity. On a horizontal scale, it could be registered as different "frequencies," giving out different "colors" of meaning. The area of the graph is the general field of meaning. In three dimensions, we would arrive at time-meaning-space, and it would be quite interesting to explore bending of this fabric by power forces.

[Weber (1968), p. 5, I think makes a mistake when he valorizes meaning on a scale where traditional social action is barely meaningful and where value- and purpose-rationality are high in meaning. Tradition is literally handed on social action and it is a set of meanings that are handed on; for example, in a caste system meaning is daily ritualized through the observance of taboos. It would be far simpler for Weber to accept that all his types draw from a field of meaning. The base unit I contend is meaning not rationality.]

Sociological explanation comes in two forms: the more general form is understanding, which is a Diltheyan empathetic relationship of investigator and the observed. The second form is Weberian causality, where intentional meaning is the basis for attributing causal action and effects in the social world (Bruun and Whimster, 2012) (pp. xxv-xxvii). Rational social action is deliberated, purposeful action, and is the basis for the much lauded concept of agency. Emotional action, as in charismatic leadership, is also a type of agency.

Latour (2007), pp. 1-14, has recently pointed out that this does not quite cover it. Latour's big objection to much of sociology and its sociologies "of" is that it assumes what has to be explained. Invoking "society" does not explain what is social about a social relationship. He is not alone in this. Luhmann (1995), pp. xxxviixliv, expressed the objection in this way: society is what is achieved in enabling interaction between societal domains. Luhmann drops a very large hint about what we should be looking for-the communicative capacity of interfaces between social domains. Of course this is not a hint, it is his theory of society. Harold Garfinkel is another notable for problematizing the social. When social interaction has become taken for granted-e.g., reading your emails over the breakfast bar-we have stopped explaining what is, at the outset, sociologically strange. A Garfinkel experiment today would confiscate all mobiles from the family table and then observe as old-style sociability stumbled back into life. The Paul at Antioch issue, first raised by Ernst Troeltsch, was sociologized by Weber as commensalism (Weber, 1968) (pp. 433-435). Eating together, culturally, is a big thing. We have to revisit the original meaning in order to retrieve the nature of the social in a relationship. I suspect in our role as instructors we are obscuring from our students the nature of the social when we outline on our power points Weber's social action typologies. It is the small font case studies, provided by Weber in Economy and Society, where understanding is secured.

Top-down societal explanations are forbidden in social relationship sociology. This is why this school of sociology has been so important. It resists the short cut of placing the explanans in society, or culture. Weber, an opponent of society as an explanatory "thing," only accepted sociology as a label once he had constructed a calculus of social relationships. Social relationships are activated by meaning propagators.

\section{RELATIONALITY AS COMMUNICATION}

We have not picked out relationality in our sociological theories because, until recently, it was subsumed within a social relationship. 
Had we chosen to look carefully, we would have found it. (This is a point analogous to the discovery in the tumultuous period of 1900-1926 of the micro granularity of the physical universe, unitized as the Planck constant-which is a very very small number, though probably not for electrons.) Because of our ability to hermeneutize the text, we are oblivious of the underlying communication technology.

In relationality, entities-individuals, actors-do not generate and create the relationship. Instead, they take their cues from some pre-existing connection that links individuals. There is a much cited article that maps the network patterns of the blogs posted, respectively, by sex workers and clients (Rocha et al., 2010). They obtained their data from online web "communities" for a period of six years, in Brazil, starting in 2004. The title of the article-"Information dynamics shape the sexual networks of Internet-mediated prostitution"-makes clear that they are proceeding from communication to relationality and then drawing some empirical conclusions about social relationships. The sharing of information forms triangles that become denser around neighboring cities. The information itself concerns health and expertise of sex workers and positive and negative satisfaction of clients. Little is said about social relationships other than how the sexual preferences are paired up between sex worker and client and how this affects the longevity of relationships. This is a sociology of sexual behavior but not one that sets out from meaning. Their use of the term "web communities" I think is misplaced. It endows the purely associational and relational character of the information being exchanged with a spurious Gemeinschaft, which is a meaning-based concept.

My general thesis is that our contemporary world is driven by ever-proliferating relationality, and this has a determining influence on the nature of social relationships of those participants in the network. Relationality is indifferent to social relationships. The latter are in some sense finitely bounded by the field of meaning. Relationality, as the word tells us, is capable of limitless extension and density.

Just what is relationality? - to pose a Garfinkel-type question. The obvious hunch is to say that relationality is based on communication, which is the direction I want to pursue-as have many others. But, on the grounds of separation, I do not want communication to be defined by meaning and intention. This is a standard definition of communication. A message is emitted via some medium to a receiver and the sender does this intentionally. The overlap with purposive rationality is pretty clear and, also, agency is privileged.

Dennett has criticized the over-emphasis given to intentionality, which he sees fully articulated by the language philosopher H. P. Grice for whom the issue is one of defining "non-natural meaning"; that is, it involves conscious meaning at all stages. (1) The sender wants to produce a response in the audience, (2) the audience-person or persons-recognize the sender's intention, and (3) the audience recognizes that the sender is fashioning his communication on the expectation that the audience has reasons to react to the message in terms of the sender's intentions [taken from Dennett (2017), p. 288]. We can find the same emphasis on assumed intentionality and reason in the example used by Weber, where he discusses a military command "ambiguousily formulated" that compels its recipient—the leader of a patrol-to work out what it means. The problem (and solution) is to understand what was meant by the sender, that is the officer who sent the message. This then allows the correct interpretation of the message (Weber, 2012) (p. 61) (Bruun, 2016; p. 43-44).

Dennett's general argument is that the human mind is populated with learned memes, which are far more important in how communication is possible than assuming always, in every communication, we return to first principles and consciously and overtly work out what was the sender's intention behind the message. The brain is an instrument that learns cumulatively on Bayesian principles-it understands on the back of accumulated experience and knows what to expect. Minds can communicate with very little sweat on the brow through the use of memes.

\section{PERNICIOUS MEMES AND DONALD TRUMP}

Memes are bits of cultural information (whose contents do not immediately have to be disclosed) that can be transmitted without full intentionality or comprehension, they are replicable, and they can either survive or disappear in an environment according to circumstances. Let us see whether this helps explain Donald Trump's elimination of his rivals in the Republican Party, which was a truly remarkable feat, executed as a hostile take-over bid. Here, we should be warned by an apt statement by Richerson and Boyd: "The price we pay for our promiscuous lust for adaptive information is playing host to sometimes spectacularly pathological cultural variants" [quoted by Dennett (2017), p. 209]. Trump introduced some truly poisonous memes into the debates (Republican primaries and presidential) through his use of Twitter. In one sense, he was on neutral grounds in the live television debates, since this was traditional media and debate. Trump, though, had the advantage of being a professional in the art of celebrity television. He could beam out more memes than the other candidates and he completely overrode normative inhibitions, insulting other candidates and repeatedly harassing the adjudicators. His poll ratings markedly rose after the 6 August presidential debate, after which Trump on both CNN and Twitter said of Megyn Kelly: "you could see there was blood coming out of her eyes, blood coming out of her wherever" (NOSE). Just got on w/thought."

Could Trump get away with this because of his celebrity status or because Twitter is an inhibition-free zone? In Social Theory after the Internet Ralph Schroeder of the Oxford Internet Institute comments on Trump's use of social media: "The role of Twitter can be singled out here; it was a transmission belt to visibility in traditional media. It did not play a decisive role once Trump was the nominee of the Republican Party, since from this point onward, the candidates of both parties were guaranteed a roughly share of media attention (and Trump could also gain attention by seeking media appearances). But Twitter did play a decisive role in his success in becoming the nominee of the Republican Party" (Schroeder, 2018). To this I would add that Trump brought the inhibition-free discourse of Twitter into the television debates, able to insult his opponents- "little Marco," "lying Ted," "crooked 
Hillary" - in a way never before seen or heard. When interviewed by the Financial Times (2/4/2017), Trump himself acknowledged the key part played by Twitter. "Without the tweets, I wouldn't be here... I have over $100 \mathrm{~m}$ followers between Facebook, Twitter [and] Instagram." [...] "Over $100 \mathrm{~m}$. I don't have to go to the fake media."

Scaff (2017), p. 21, in a lecture given in December 2015, offers a Simmelian analysis of politics in the digital age. "The entire technical apparatus of instantaneous communication and dissemination of visual imagery, and so on, a Simmelian compression of time and space-has created an opening for a new kind of demagogue, a media personality, a creature of the new media who thrives on the sensational, exaggerated and aggressive language, attention-grabbing theatrical performance, and who valorizes and legitimates in the audience the strongest of the emotions: anger, fear, and resentment." The same argument can be deployed to explain the recent United Kingdom referendum on leaving the European Union where the populist Nigel Farage followed the same communication strategy.

These quotes and the events themselves do not require any further emphasizing in order to grasp the enormous significance of what we are living through. But there is more to be said about how these phenomena can be analyzed in terms of relationality.

Demeaning a high profile TV journalist in the way, Trump did constitute the use of a very pernicious meme. It layers back through street vernacular and male bonding talk to notions of purity, taboo-but here seemingly no danger. The meme also becomes an accretion, repeatable in a way never before allowed. In Dennett's terminology it changes the Umwelt, offering beleaguered white men a new and substantial "affordance" (Dennett, 2017; p. 79); so also his tweets in other spheres-imploding Obamacare, fake news, "Gitmo" prisoners, Obama’s wire-tapping, illegal immigration from seven suspect countries, negative polls are fake news, opinion of a so-called judge, Iran is playing with fire, Mexico, etc.

The meme, therefore, gives us a way of describing messages without an accompanying interpretive scaffolding. This makes the message not overdependent on meaning and allows a clearer run for relationality. Dennett is not interested in this step, for he wants to reduce memes to words-a kind of lexical individualism, and with this to get back to his main concern which is to analogize brains to computers. The notion of computer processing gives him considerable leeway to pursue that avenue. Dennett is an important public philosopher, but his theories move away from the sociological.

My thinking on communication has been shaped by the work of the Canadian theorist (and economic historian) Harold Innis [discussed by Whimster (2007), pp. 196-198; Whimster (2016), pp. 448-453]. Marshall McCluhan, his junior in the faculty at Toronto, popularized Innis with the slogan "The medium is the message." This rather diverted from Innis's more substantial argument that communication and their media should be thought of as technologies, which have enabling and restraining capacities. Language in words is a technology, an alphabet and writing is a technology. To illustrate, too briefly, the Inca empire was dependent on a communication technology of a belt of dangling strings, the quipu. The length of the strings and the position of knots performed as a decimal number system. It allowed the empire, which stretched the length of the Andes, to operate what would have been termed an oriental despotism. Populations were counted, moved hundreds of miles, enslaved, and ordered to accomplish huge economic projects on the basis of inputoutput accounting (not their term obviously). This is described by Given-Wilson as bureaucracy without alphabetic writing (Given-Wilson, 2016; pp. 81-101). There was no alphabet, nor any files, which in Innes's terminology are the technology of communication of modern bureaucracy. Or, to make another large argument, Weber's Protestant ethic thesis can more profitably be understood as the emergence of the twinned technologies of European vernacular languages and printed books (Whimster, 2007; pp. 198-203).

The technology of communication is the medium through which social media operate. Social media with their proliferating networks of relationality flow through the digital technology of communication. Memes-political, personal, cultural, marketing-are enabled (and depraved) by this technology. Communication, and the form of its technology, gives us the granularity of relationality. The human subject is an accessible object as a meme hits upon a receiver device, such as a mobile phone. The twitter sphere, the digital communications sphere, are full of electron-messages that combust into some kind of meaning at each relay point, which may be thought of as approaching random collisions such is the immensity of social media.

In offering a theoretical reconceptualization of communication seen in relational terms, in further work it will be important to consider more fully the meme as an important empirical referent. Memes have to be created in the first instance, and confining the discussion to Trump they are produced in a manner resembling fast-track ideology. The majority of phrases entering the twittersphere do not attain meme status. The effectiveness of Trump's tweets is that create an affordance, where none before was in play.

\section{A THEORY OF COMPLEMENTARITY}

The final stage in my argument is complementarity. We have social relationships whose granularity resides in meaning, and we have relationality whose granularity is measured in extensive and intensive networks platformed by the many forms of communication technology. Relationality on its own makes no sense at all. There has to be meaning generators and a field of meaning for there to be any purpose to relationality. My main point, given a skeletal outline in this presentation, is to keep and develop relationality and its principles separate from social theories of meaning and their attendant elaboration of social relationships. In this way, to use Scaff's political example, we can explain how creatures of the new media are able to mobilize the strong emotions of anger, fear, and resentment on a mass scale.

We may like to think of this as social theory learning from the waves and particle debates in quantum mechanics, but only to the extent that waves and particles were argued (by Niels Bohr et al.) to have a complementary relationship in an epistemological sense that the anschaulich (here, the physical) was being approached with two different experimental set-ups (Pais, 1991; pp. 309-316). Waves of meaning and particles of communication 
are a pleasing but mistaken analogy. The way to go, more likely, is the superposition(s) of relationality upon meaning, giving different valences to meaning at any one network point. Also we would need to note that meaning is continuous and it becomes unitized only after investigator impositions (data variables). Changes in communication technologies may colloquially be termed quantum jumps, but more accurately they should be called qualia leaps, or better, switches between qualia.

\section{REFERENCES}

Bruun, H. H. (2016). Weber's sociology - 'verstehend' or 'deutend'? Max Weber Stud. 16, 39-50. doi:10.15543/MWS/2016/1/4

Bruun, H. H., and Whimster, S. (2012). "Introduction" to Max Weber Collected Methodological Writings, ed. H. H. Bruun (Abingdon, New York: Routledge).

Dennett, D. C. (2017). From Bacteria to Bach and Back. The Evolution of Minds. London: Allen Lane.

Given-Wilson, C. (2016). "Bureaucracy without alphabetic writing. Governing the Inca Empire, c. 1438-1532," in Empires and Bureaucracy in World History. Fromm Late Antiquity to the Twentieth Century, eds P. Crooks and T. H. Parsons (Cambridge: Cambridge University Press), $81-101$.

Hopkins, N. (2007). Charisma and responsibility. Max Weber, Kurt Eisner and the Bavarian revolution of 1918. Max Weber Stud. 7, 185-211. doi:10.15543/ MWS/2007/2/5

Latour, B. (2007). Reassembling the Social. Oxford: Oxford University Press.

Luhmann, N. (1995). Social Systems, ed. J. Bednarz Jr. (Stanford: Stanford University Press).

Mucha, J. (2003). "The concept of 'social relations' in classic analytical interpretative sociology: Weber and Znaniecki," in Research Networks No 21 Social Theory, ESA Conference. Murcia.

Nan, L. (2001). Social Capital. A Theory of Social Structure and Action. Cambridge: Cambridge University Press.

Pais, A. (1991). Niels Bohr's Times, In Physics, Philosophy, and Polity. Oxford: Clarendon Press.

Powell, C., and Dépelteau, F. (eds) (2013). Conceptualizing Relational Sociology. Ontological and Theoretical Issues. New York: Palgrave.

Rocha, L., Liljerosb, F., and Holmea, P. (2010). Information Dynamics Shape the Sexual Networks of Internet-Mediated Prostitution. Available at: www.pnas.org/ cgi/doi/10.1073/pnas.0914080107
Finally, we might want to consider whether sociology as a discipline has fallen back because it has not been able to incorporate a complementary theory of communication relevant to our times.

\section{AUTHOR CONTRIBUTIONS}

The author confirms being the sole contributor of this work and approved it for publication.

Rovelli, C. (2016). Reality Is Not What It Seems. The Journey to Quantum Gravity. London: Allen Lane.

Scaff, L. (2017). Political leadership and political education. Max Weber Stud. 17, 12-23. doi:10.15543/MWS/2017/1/3

Schroeder, R. (2018). Social Theory after the Internet: Media, Technology and Globalization, Chap. Chap.3. London: UCL Press.

Scott, J. (2017). Social Network Analysis. London: SAGE.

Swedberg, R. (2014). The Art of Social Theory. Princeton: Princeton University Press.

Wagner, G. (2012). Die Wissenschaftstheorie der Soziologie. Ein Grundriss. Munich: Oldenbourg Verlag.

Weber, M. (1968). Economy and Society. New York: Bedminster Press.

Weber, M. (2012). Max Weber Collected Methodological Writings, eds H. H. Bruun and S. Whimster (London and New York: Routledge).

Whimster, S. (2007). Understanding Weber. London and New York: Routledge.

Whimster, S. (2016). "Empires and bureaucracy: means of appropriation and media of communication," in Empires and Bureaucracy in World History. From Late Antiquity to the Twentieth Century, eds P. Crooks and T. H. Parsons (Cambridge: Cambridge University Press), 437-456.

Winnicott, D. N. (1960). The theory of parent-infant relationship. Int. J. Psychoanal. $41,585-595$.

Conflict of Interest Statement: The author declares that the research was conducted in the absence of any commercial or financial relationships that could be construed as a potential conflict of interest.

Copyright $\odot 2018$ Whimster. This is an open-access article distributed under the terms of the Creative Commons Attribution License (CC BY). The use, distribution or reproduction in other forums is permitted, provided the original author(s) and the copyright owner are credited and that the original publication in this journal is cited, in accordance with accepted academic practice. No use, distribution or reproduction is permitted which does not comply with these terms. 